\title{
PHARMACOLOGICAL AND NON-PHARMACOLOGICAL TREATMENT PROFILE OF OSTEOARTHRITIS IN A MUNICIPALITY IN THE NORTH CENTRAL REGION OF PARANÁ
}

Vinícius Shinoda Pereira ${ }^{1, \star}$, Gabriel Dallazem de Farias ${ }^{1}$, Fernanda Maria Borghi ${ }^{1}$

1.Centro Universitário de Maringá, Maringá (PR), Brazil.

*Corresponding author: shinoda.vinicius.pereira@gmail.com

\section{BACKGROUND}

Osteoarthritis is a joint disease characterized by progressive cartilage degeneration associated with inflammatory phenomena. It is age-related and has a multimodal treatment.

\section{MATERIALS AND METHODS}

This is an observational, descriptive and retrospective study, through the investigation of electronic medical records of 363 patients of Maringá Health Management System. The pharmacological and nonpharmacological treatment profiles, age, sex, ICD 10 subcategory and exam requested by physician were analyzed and compared with ESCEO's and OARSI's treatment algorithms for osteoarthritis.

\section{RESULTS}

The average age of the patients were 64.6 years, $71.9 \%$ of whom were female; $74 \%$ were attended by orthopedics, $21 \%$ by rheumatology and 3\% by general practitioners. One hundred seventy-eight patients were diagnosed as M170 (bilateral primary gonarthrosis), 87 as M159 (unspecified polyarthrosis), 49 as M171 (unilateral primary osteoarthritis, unspecified knee), 40 as M150 (generalized primary osteoarthrosis) and 9 as M160 (bilateral primary osteoarthritis of hip). The most prescribed drugs were ibuprofen, paracetamol and dipyrone (complete list on Table 1). In the nonpharmacological management, there were 100 referrals to physiotherapy (27.5\%), 34 for physical activity (9.3\%) and 5 for weight loss (1.3\%). About investigation tests, there were 143 referrals to X-ray (39.4\%), 68 to USG (18.7\%) and 42 laboratory tests (11.5\%).

Table 1. Drugs in decreasing order of prescriptions.

\begin{tabular}{ccc}
\hline Pharmacological management & N & $\%$ \\
\hline Ibuprofen & 118 & 32.5 \\
\hline Paracetamol & 95 & 26.2 \\
\hline Dipyrone & 80 & 22.0 \\
\hline Amitriptyline & 39 & 10.7 \\
\hline Diclofenac & 26 & 7.2 \\
\hline Codeine & 24 & 6.6 \\
\hline Fluoxetine & 23 & 6.3 \\
\hline Dexamethasone & 21 & 5.8 \\
\hline Glucosamine sulfate & 17 & 4.7 \\
\hline Arnica gel & 16 & 4.4 \\
\hline Hydroxychloroquine & 12 & 3.3 \\
\hline
\end{tabular}




\section{CONCLUSION}

ESCEO and OARSI establish that physical activity and weight loss for those overweight should be recommended in osteoarthritis. Although the results of the study are not in accordance with these recommendations, it is possible that physicians have recommended it, but not described in the medical record. OARSI also recommends caution regarding the dose and time of use of oral NSAIDs, prescribing it preferably for individuals without comorbidities. In our study, ibuprofen was the most prescribed drug, which may be due to the fact that this medication is provided with no coasts by the public health system. Furthermore, paracetamol, also provided by the health system with no coasts, appears as the second most prescribed drug but is not even recommended in these guidelines.

\section{REFERENCES}

1. Bannuru RR, Osani MC, Vaysbrot EE, Arden NK, Bennell K, Bierma-Zeinstra SMA, et al. OARSI guidelines for the non-surgical management of knee, hip, and polyarticular osteoarthritis. Osteoarthritis Cartilage. 2019;27(11):1578-89. https://doi.org/10.1016/j. joca.2019.06.011

2. Bruyère O, Honvo G, Veronese N, Arden NK, Branco J, Curtis EM, et al. An updated algorithm recommendation for the management of knee osteoarthritis from the European Society for Clinical and Economic Aspects of Osteoporosis, Osteoarthritis and Musculoskeletal Diseases (ESCEO). Semin Arthritis Rheum. 2019;49(3):337-50. https://doi.org/10.1016/j.semarthrit.2019.04.008

3. Heegde FT, Luiz AP, Santana Varela S, Chessell IP, Welsh F, Wood JN, et al. Noninvasive mechanical joint loading as an alternative model for osteoarthritic pain. Arthritis Rheumatol. 2019;71(7):1078-88. https://doi.org/10.1002/art.40835

4. Rezende MU, Campos GC, Pailo AF. Conceitos atuais em osteoartrite. Acta Ortop Bras. 2013;21(2):120-2. http://doi.org/10.1590/ S1413-78522013000200010

5. Zeng C, Dubreuil M, LaRochelle MR, Lu N, Wei J, Choi HK, et al. Association of tramadol with all-cause mortality among patients with osteoarthritis. JAMA. 2019;321(10):969-82. https://doi.org/10.1001/jama.2019.1347 